\title{
LAS FUERZAS ARMADAS EN LA TRANSICIÓN DEMOCRÁTICA ESPAÑOLA
}

\author{
SABINO FERNÁNDEZ CAMPO \\ Ex-Jefe de la Casa de S.M. el Rey
}




\title{
LAS FUERZAS ARMADAS EN LA TRANSICIÓN DEMOCRÁTICA ESPAÑOLA
}

POR

\author{
SABINO FERNÁNDEZ CAMPO \\ Ex-Jefe de la Casa de S.M. el Rey
}

Agradezco, ante todo, que os hayáis acordado de mí para pronunciar unas palabras en esta prestigiosa Cátedra "General Castaños" cuando me encuentro en la más absoluta de las reservas desde el punto de vista militar y en una situación alejada de cualquier preocupación activa. Más bien con una preocupación que pudiéramos llamar terminal.

Cuando somos jóvenes, nos preocupa el camino por el que va a ir nuestra vida. Cuando somos viejos, nos preocupa el camino por el que va a venir nuestra muerte. Yo estoy dentro de esta segunda preocupación, pero, en todo caso, muy reconocido de que hayáis brindado esta oportunidad de estar hoy con vosotros.

Muchísimas gracias también al Teniente General Muñoz Grandes por sus amables palabras de presentación, muestra indudable de unos sentimientos de amistad, de compañerismo y de afecto que le hacen apartarse de una realidad mucho más vulgar.

Puesto que mi disertación va a tener un inevitable ingrediente militar, me gustaría comenzarla con una frase de Alfredo de Vigny, cuando en su obra "Servidumbre y grandeza de las Armas", se refiere al Ejército como "esa raza de hombres siempre desdeñada o glorifica-

(*) Conferencia pronunciada en la Cátedra "General Castaños», Sevilla, 26 de noviembre de 1997. 
da con exageración, con arreglo a la medida en que las naciones la encuentran útil y necesarian.

A lo largo de mis años, me ha correspondido vivir ambas alternativas. $Y$ me permito afirmar que ni la glorificación exagerada es buena, ni el desdén es inteligente.

Siempre, a través de mi vida, he procurado someterme a un consejo que repito con frecuencia, practico cuando puedo y no me ha dado malos resultados: "Habla nada de ti, poco de los demás y mucho de las cosas». Pero hoy, después de meditarlo bastante, he decidido hacer lo contrario de lo que es normal en mi, para relatar de forma personal y anecdótica, aún a costa de colocarme en un relativo primer plano, algunos sucedidos subjetivos de los que puedan deducirse, aunque yo no lo haga claramente, consecuencias e interpretaciones más generales y objetivas. A vosotros os dejo, con plena confianza, la labor de deducir con mayor amplitud lo que tan sólo apunto someramente.

Os pido disculpas, pues, por ejercer como excepción este protagonismo, vulgar y de escasa altura, pero que quizá pueda encerrar más interés que un relato global, ya recogido con este carácter en diversos libros, artículos y publicaciones de toda clase y hasta en Historias de España de los tiempos modernos.

Mi edad, que empieza a resultarme alarmante, me hace formar parte de una generación, ya muy pasada de actualidad, que vivió importantes momentos de una época repleta de interés y yo puedo recordar muchos de ellos porque me han dejado un recuerdo imborrable. No es lo mismo enterarse de los acontecimientos a través de relatos, muchas veces lógicamente opuestos y partidistas, que haberlos contemplado de una manera directa y juzgarlos ahora, aunque no sea más que como símbolos significativos, de una manera imparcial y serena.

"La importancia de los acontecimientos -decía Andrés Mauroissiempre escapa a quienes los han presenciado".

$Y$ esto, a primera vista, parece muy cierto, porque la historia es tal vez como un cuadro que ha de contemplarse de lejos, desde una perspectiva no demasiado cercana, para poder contemplar e interpretar el conjunto. Pero tampoco deja de ser verdad que la obra de arte pictórica se compone de un conjunto armónico de pinceladas que proporcionan luz o sombra, relieves o veladuras, detalles al parecer insignificantes, pero que constituyen componentes imprescindibles de la totalidad, lograda con la acumulación de las partes y capaz de producirnos una impresión general. 
Las ciencias políticas, con sus teorías básicas y remotas constituyen fuentes imprescindibles para conseguir deducciones más actuales. Pero también en la actualidad, sus pinceladas más elementales pueden integrarse para formar un panorama más explicable y práctico. Existe, por lo tanto, hasta una obligación de aportar esas experiencias personales y, en todo caso, confiar en merecer el perdón al hacerlo, si dentro de la mayor modestia habla uno un poco de sí mismo y con ello se ayuda a conocer a los demás, y a descubrir, aunque sea en un mínimo grado la explicación de algunas cosas.

Al fin y al cabo, la historia y la política están muchas veces tejidas o condicionadas por pequeños sucesos que parecen carecer de trascendencia, pero que pueden convertirse en aquellos momentos estelares de la humanidad sobre los que escribió Stefan Zweig.

Se trata de que uno estuvo allí en ese instante crucial, aunque fuera en una posición carente de toda importancia. Como no la tiene el espejo que, sin embargo, puede reflejar una obra de arte o la belleza de un rostro.

Nada es cierto si no es expresado, nada es expresado si no es vivido.

El talento del historiador o del que quiere comprender la historia, consiste en formar un conjunto verdadero con extremos que no son ciertos sino a medias, porque la verdad se reconstruye con datos, pero también con interpretaciones.

Por eso quisiera hoy, con la mayor franqueza y ecuanimidad, apoyado en hechos casualmente vividos, hacer un análisis del papel jugado por las Fuerzas Armadas durante el período de la transición democrática en España, contemplándolo desde dentro, como una parte que fui y seguiré siendo, cualquiera que sea la situación en que me encuentre, del Ejército español.

Tal vez para desarrollar el contenido del título que hoy abordo habría de comenzar por hacer, de una parte, un estudio histórico, sociológico y hasta psicológico de las Fuerzas Armadas de nuestro país, y determinar, de otra parte, cuándo empieza y cuándo termina la transición.

Pero no va a haber demasiado tiempo para ello. Ni la historia es corta ni la determinación sencilla.

Sí diré que la realidad nos muestra desde el pasado una frecuente propensión de los militares a intervenir en la vida política, cuando se presentaban momentos que juzgaban cruciales. Por eso son numerososo los "pronunciamientos" que a través de los años se produjeron, inspirados muchos de ellos por movimientos liberales. 
En cuanto a la transición, me atrevo a decir que la vida española -quizá como la de todos los países- es de alguna forma una continua transición a la que resulta muy complicado poner límites.

En la historia de los pueblos es difícil puntualizar cuando empiezan y cuando terminan, las eras, las épocas, los períodos o las transiciones. Puede haber hechos señeros o simbólicos que parecen representar el momento del cambio, pero no son más que signos destacados, precedidos y seguidos de otros antecedentes y de otras consecuencias.

El río no es el agua que en un momento pasa por un lugar determinado entre sus orillas, sino todo el caudal que ha recorrido su cauce, que lo recorre y que lo recorrerá en el futuro. Para que la transición española pudiera tener lugar dentro del Derecho y sin violencia, hubo de empezar a institucionalizarse con anterioridad, a fin de que el cambio no tuviera lugar bruscamente, sino apoyándose en unas normas jurídicas que permitieran la evolución pacífica.

Quizá pudiéramos también preguntarnos si esa evolución ha terminado $y$ hemos alcanzado ya la perfección democrática.

Entre los miembros de las Fuerzas Armadas y prescindiendo de excepciones que siempre existen, el malestar era, en general, muy profundo en los tiempos previos al desencadenamiento de la guerra civil de 1936.

En una reciente edición de la obra de Miguel Maura, "Así cayó Alfonso XIII...", el autor se refiere a la actuación de Don Manuel Azaña en su primera etapa al frente del Ministerio de la Guerra y que encerraba, a la vez, un gran acierto y un gravísimo error. Las medidas incluidas en su reforma respondían, sin duda, a un imperativo nacional. Había que adaptar los efectivos, la organización y las plantillas de los Mandos militares a las necesidades y a las posibilidades de la Nación.

"Los anteriores proyectos de reforma, elaborados durante la Monarquía constitucional unos y durante la dictadura de Primo de Rivera otros, tropezaron con obstáculos tradicionales y quedaron en simples proyectos", dice Miguel Maura.

El cambio de régimen permitió una mayor decisión y radicalidad en las medidas. Pero el entonces Ministro de la Guerra fue más rotundo e hirientes en sus palabras que en sus obras. La referencia que hizo públicamente a la "trituración" del Ejército, dejó una huella imborrable que constituyó la causa de muchos acontecimientos posteriores.

Quizá sirvió también de experiencia para que en otras ocasiones más recientes se considerase preferible abstenerse de emplear términos 
tan amenazadores, para dirigir en cambio las energías a llevar a cabo con profundidad $y$ radicalidad lo que no se proclamaba tan ofensivamente.

Pero ya antes de la proclamación de la República se habían producido en las Fuerzas Armadas alarmantes síntomas de desunión y de conflictos, manifestados en actividades subversivas, a partir de 1925. El más grave en 1929, por la resistencia del Arma de Artillería a las disposiciones de Primo de Rivera para suprimir las escalas cerradas y reducir su espíritu de Cuerpo. Las sublevaciones de Jaca y Cuatro Vientos en 1930, son también muestras evidentes de peligrosas divisiones.

La desorientación causada por el final de la Dictadura, con los confusos intentos de restablecer una situación democrática, habían dejado también en la Milicia una impresión de desengaños e ingratitudes que, en ocasiones, influyen de manera decidida en la conducta de las personas y en las consecuencias para la Historia.

A modo de ejemplo de cómo una circunstancia personal puede traducirse en cambios trascendentes, me referiré a la propia proclamación de la República del 14 de abril de 1931.

La actitud que se observó con respecto al General Don Miguel Primo de Rivera, Marqués de Estella, cuando se puso término a su mandato excepcional, pudo dar lugar a que la República llegara a establecerse en España, tras unas elecciones municipales, en vez de mantenerse el tradicional sistema monárquico.

Bien es cierto que fueron muchos más los motivos que se acumularon para que el acontecimiento se produjera. Pero entre ellos, siempre puede existir uno decisivo.

La amistad, el compañerismo y la camaradería entre el General Primo de Rivera y el General Sanjurjo, que se fraguaron en tiempos de guerra, durante la campaña de Marruecos, originaron un lazo indisoluble, difícil de quebrarse en la Milicia. Y así, el Marqués del Rif no pudo evitar la impresión que le produjo la triste suerte de su compañero, muerto en París, casi puede decirse que de pena, ante abandonos, olvidos y desprecios.

El Ayudante de Sanjurjo, el entonces Comandante Emilio Esteban Infantes, escribe: "Faltaría a la verdad si no dijera que la caída o retirada de Primo de Rivera disgustó extraordinariamente a Sanjurjo. Estaba convencido de que, de una u otra forma, el exilio del Presidente a París no fue en él un acto totalmente voluntario. Los hilos de la intriga desconcertaron al Marqués de Estella y su muerte afectó tan profundamente a su compañero el General Sanjurjo, que no fue capaz de olvidarlo». 
Y así, el General Sanjurjo, Director General de la Guardia Civil en abril de 1931, al no responder del apoyo de sus fuerzas a la Monarquía y acudir a ponerse a las órdenes del sorprendido Gobierno Provisional de la República, fue un factor determinante para que ésta se proclamara.

¿Hubieran llegado al poder con tanta facilidad los republicanos de haber sido otra la actitud del General Sanjurjo?

$Y$, sin embargo, el entonces Director General de la Guardia Civil demostró después, el 10 de agosto de 1932, que no había abandonado sus convicciones.

Por eso, aunque insista tal vez demasiado en este aspecto que al fin y al cabo pone de relieve el carácter militar, no me resisto a relatar de pasada, como anécdota significativa, lo que dijo el General Sanjurjo en el Consejo de Guerra después de la frustrada intentona, cuando el Presidente del Tribunal le preguntó:

\section{- ¿YY con quién contaba Vd. para la sublevación?}

- "Si hubiera triunfado, con todos, incluido Vd. Como he fracasado, con nadie", fue la respuesta de Sanjurjo.

Es de señalar que el General admitió decididamente su acción y asumió toda la responsabilidad, en descargo de otros compañeros, en unos tiempos en que existía la pena de muerte. Sanjurjo fue indultado de la que se le había impuesto, pero otro General, que se sublevó pocos años después, recordó en aquella ocasión la frase de que "el militar que se subleva, ha ganado su derecho a morir". Una actitud que pudiera haber sido tenida en cuenta en situaciones semejantes en las que, además, no existía el riesgo del fusilamiento, y con la que se hubieran evitado deplorables consecuencias para varios militares $y$, en definitiva, para las Fuerzas Armadas.

No voy a detenerme en el comentario de otros posibles intentos de golpes de Estado militares, propiciados por líderes derechistas que trataron de tentar a Generales como Fanjul, Goded o el propio Franco sobre los que Azaña comentó: "No creo que haya ninguno dispuesto a jugarse nada en serio". Tampoco hay tiempo para meditar sobre la discutida suposición de si se estaba preparando o no un alzamiento de la extrema izquierda, cuando tuvo lugar el de los militares el 18 de julio de 1936.

Lo cierto es que antes de esa fecha, la situación en España era cada vez más tensa. $Y$, sin embargo, aunque pudiera parecer que existía una división radical, unos campos opuestos bien definidos, no era exactamente la realidad, por lo cual las cosas se complicaban aún más. Como 
dice un historiador -Ricardo de la Cierva- la situación era mucho más compleja. Es cierto que el mapa electoral de entonces sugiere las zonas enfrentadas pocos meses más tarde en la guerra civil. Pero no se trata de zonas nitidas, monocolores, una roja y otra blanca. En las dos zonas latía su porción relativa de la otra media España, de izquierdas y de derechas, de las dos Españas. Esto es lo que se ignoró casi siempre una vez declarada la guerra. Este es el origen de las quintas columnas y de los entusiasmos con que se recibía a los vencedores cuando entraban en una ciudad. Las elecciones habían sido el choque de dos entusiasmos y de dos miedos. De ellos saldría, inexorablemente, la guerra civil. Pues de uno y otro lado flotaba la idea del enfrentamiento violento.

En el año 1934, hay un texto revelador de Manuel Azaña: «El fantasma del rencor, el fantasma del amor propio herido, el fantasma de la cólera, el fantasma del miedo, sobre todo el fantasma del miedo. Yo no temo a nada tanto como al miedo, no por el propio miedo, sino porque el miedo es el peor consejero de la polítican. Y en su discurso del día 3 de abril de 1936 en las Cortes, Azaña detecta de nuevo con gran precisión las "dos corrientes de pánico que sacuden diariamente el país".

Hasta cierto punto, sólo hasta cierto punto, esta situación general se reflejaba tambien en el Ejército. Se habian producido intromisiones izquierdistas en las Fuerzas Armadas. Como en el resto de la sociedad, también en las Fuerzas Armadas se manifestaban tendencias opuestas. Había advenedizos que pretendian obtener favores o lograr situaciones de privilegio en la nueva situación, pero la mayoría continuaban fieles a sus principios y a las virtudes militares clásicas.

Programas izquierdistas en que superando la "trituración de Azaña, se preconizaba la supresión de los ejércitos permanentes y el armamento general del pueblo; graves incidentes alternativos que culminaron con la muerte del líder de la derecha, Don José Calvo Sotelo, condujeron -sin que entremos en más detalles- a un golpe de Estado militar, que sin duda venía incubando desde hacía tiempo y que en verdad fracasó rotundamente, puesto que en lugar de producir el cambio súbito de las circunstancias, se prolongó en una guerra civil de tres años de duración.

Por eso, lo que se pretendía fuera un rápido "pronunciamiento", vino a suponer una verdadera movilización, en las dos zonas en que España se dividió, que afectó principalmente a las jóvenes generaciones de una y otra.

Se produce, pues, una incorporación civil que después se prolonga en las Fuerzas Armadas y que va a marcar en lo sucesivo tanto a los derrotados como a los que obtienen la victoria. 
Una incorporación civil en la que me siento comprendido y que me da pie a relatar una pequeña historia que, al afectarme, proporciona a esta narración el carácter anecdótico a que al principio de mi intervención me refería y del que confío puedan deducirse consecuencias mucho más ámplias que las del simple episodio personal.

Nos encontrábamos ya en esa transición que -repito- no estoy seguro de cuando empezó ni cuando va a completarse. Yo era entonces Subsecretario de la Presidencia del Gobierno, en el primer Gabinete de la Monarquía. Había dado un salto provisional desde la Milicia a la Administración civil. Mi Ministro, Alfonso Osorio, aparte de ejercer eficazmente ese cargo en aquellos primeros tiempos, realizaba una inteligente labor política para conseguir alianzas y apoyos de personas o sectores que pudieran agruparse y colaborar en los delicados momentos del cambio.

$Y$ una noche se organizó una cena, con un reducido número de comensales, en la casa de un excelente amigo, dilectante de la política en la que nunca intervino directamente, pero estuvo siempre interesado. Era el padre del que fue Ministro, Matías Rodríguez Inciarte. Aparte de Alfonso Osorio $y$ otras personas conocidas, el invitado principal era nada menos que Don José María Gil Robles, el que había sido destacado líder de la derecha española antes de la guerra civil.

Resultaba muy interesante conocer su punto de vista con respecto a la situación posterior a la muerte de Franco y al período inicial de la transición al que estábamos asistiendo.

Le había visto y escuchado en mítines y conferencias, pero era la primera vez que tenía la ocasión de asistir directamente a un encuentro con Don José María en persona, y quedé profundamente impresionado por su categoría, su gran cultura y la brillantez de su palabra fácil, el cúmulo de sus conocimientos y la amenidad con que relataba recuerdos interesantísimos y emocionantes, como la forma casual en que, al realizar un viaje fuera de Madrid, se salvó de ser asesinado la noche en que mataron a Calvo Sotelo.

Era subyugante su manera de relatar anécdotas del pasado anterior al 18 de julio de 1936 y escuchar de su propia voz sucesos que contó o no llegó a contar en algunos de sus libros.

Le escuchábamos extasiados, con la mayor admiración y resultaba difícil interrumpirle, hasta que después de la cena se montó un pequeño coloquio. Fueron unos momentos deliciosos e interesantísimos y reconocí su destacada personalidad, cualesquiera que hubieran sido sus aciertos o sus errores en los complicados tiempos en que ejerció la política. 
Al fin empezaron los asistentes a formular preguntas, manifestar opiniones o establecer pronósticos y planes de futuro, convirtiéndose la conversación en algo más generalizado que el monólogo atrayente de Don José María Gil Robles.

Permanecí callado, sin atreverme a intervenir ante personas tan singulares, tomando mentalmente nota de cuanto se decía, se opinaba y se proyectaba. Pero cuando se trató precisamente del tema de la iniciación de la guerra civil española, me permití participar con cierta timidez, para apuntar alguna opinión que ni siquiera recuerdo ahora. Creí que el tema me afectaba, puesto que por las edades de los contertulios -unos mayores y otros más jóvenes que yo- no les había correspondido tomar parte en la penosa contienda que nos enfrentó a los españoles.

Entonces Don José Maria, sin perder su amabilidad, educadísimo, paternal y en tono cariñoso, después de mirarme de arriba a abajo como si acabara de descubrirme, me dijo con casi inadvertible displicencia:

- "Vd. de eso no sabe nada. Entonces era un chiquillo".

Con todo el respeto que me inspiraba el Sr. Gil Robles y me sigue inspirando su memoria, sentí como un vuelco en el estómago $y$, sin quererlo, salió a relucir ese condenado amor propio que todos llevamos dentro.

— "Sí, Don José Maria, "le contesté". Era un niño y no estaba ni muchísimo menos tan enterado de la situación general como sin duda lo estaban las personalidades políticas que de una u otra forma, desde una $u$ otra posición, tenían en sus manos los destinos de España. Y yo, como otros tantos muchachos de mi edad, sin saber nada de las alturas en las que Vds. se movian, experimenté cómo en mi vida se producía un cambio radical. Vi interrumpida la felicidad y la paz de una familia normal. Se aplazó durante años la terminación de mi carrera de Derecho que estaba a punto de finalizar. Pero, sobre todo, pasé miedo y frío y calor y hambre. Contemplé cómo morían amigos tan jóvenes como yo, compañeros de Instituto y de la Universidad, y sufrí el dolor inmenso de enfrentarme con otros españoles de mi propia generación, que tal vez habíamos jugado o nos habiamos divertido juntos, $y$ ahora luchaban en las filas contrarias".

"Y quedé, después de tanto horror, mezclado con gestos de bravura, de sacrificio y de compañerismo, sujeto a las filas del Ejército una vez finalizada la campaña, porque la siguiente conflagración europea hizo que no se nos pudiera licenciar en bastantes años. Pues bien, ese dolor, ese sufrimiento mío y de mi familia; el de tantos españoles; las destrucciones materiales y morales; las penurias y calamidades que si- 
guen a toda guerra y que se intensifican si se desarrolla en el propio territorio; toda esa tragedia, no fue evitada por los políticos profesionales y experimentados que, después de su fracaso, pusieron tierra de por medio. Si, Don José María, perdóneme Vd. Yo era entonces un chiquillo, pero lo que tuve que padecer me permite opinar, aunque mi opinión sea vulgar, ingenua y equivocada".

Se produjo un silencio profundo e incómodo. Todos, menos el antiguo jefe de la CEDA, me miraban sorprendidos y con aire de recriminación.

Siguió el debate, en el que ya no tuve ni deseos ni oportunidad de meter baza y se acabó la reunión. Había tenido lugar en la calle Hermosilla, a una altura desde la que mediaba un corto trayecto hasta la de Velázquez, donde vivía Gil Robles. Decidimos acompañarle hasta su casa a pie. $Y$ como lloviznaba ligeramente, nos proporcionaron unos paraguas. Don José María procuró emparejarse conmigo y caminamos los dos solos, bajo el que yo sostenía.

Entonces me cogió del brazo, me lo apretó leve y afectuosamente, y rompió su actitud callada, como pensativa, para decirme:

- "Tenía Vd. toda la razón».

Sinceramente, me emocionó. En tan pocas palabras me había expresado el reconocimiento de los errores cometidos por los viejos políticos y del sacrificio de una juventud que no tuvo en sus manos intervenir para evitar lo que sucedió, por una falta de comprensión y de acuerdo; por no pensar lo suficiente en una España a la que había que colocar por encima de egoísmos partidistas o pasiones personales.

Pero esa juventud de uno y otro bando -pues siento el mayor respeto por los que lucharon de verdad en el opuesto al mío- fue la que hubo de enfrentarse en una contienda que queremos - $y$ logramos- olvidar, pero que nos dejó marcados y cambió nuestro destino.

Saco a relucir esta pequeña historia personal, para extenderla a una situación general y para rendir un tributo de admiración a la caballerosidad de Don José María Gil Robles por la comprensión que reflejó en una sola frase, quizá mas expresiva que el contenido de sus libros, entre los cuales no he dejado de leer: "No fue posible la paz".

Pero también es significativa esta anécdota, porque creo que puede constituir como el compendio simbólico de a donde conduce en ocasiones el no saber sacrificar una parte de los propios criterios para evitar el gran sacrificio del enfrentamiento trágico. 
Creo que pueden deducirse muchas cosas de este recuerdo de un viejo político que supo conceder la razón a una persona tan insignificante como yo, pero que en aquel momento venía a representar a toda una generación que se integró después en gran parte dentro de las Fuerzas Armadas a las que quiero dedicar mi comentario desde el punto de vista de su participación en la transición democrática.

Porque para hablar de las Fuerzas Armadas durante ese período, hay que hacer algunas consideraciones previas, pues la prolongación de un golpe de estado en una guerra civil de larga duración origina en ellas un cambio fundamental y se modifica su normal integración.

Alargaría demasiado mis palabras revisar la conducta de algunos militares profesionales que pretendieron ser neutrales ante el alzamiento y que sufrieron las consecuencias de su falta de decisión. Pero, durante la dolorosa contienda, los de uno y otro bando que originaron o se enfrentaron con la sublevación y que se encontraban en cada uno de aquéllas por motivos idealistas unas veces o simplemente por situación geográfica otras, era natural que por su formación, sus conocimientos y las enseñanzas recibidas en las Academias militares, se situasen inmediatamente en posiciones elevadas del Mando, tanto más prominentes cuanto mayor fuera su graduación.

Se produce también el retorno en la zona nacional, de gran número de Jefes y Oficiales que se habían acogido a la especial ley de retiro establecida por Azaña.

Surgen así las "habilitaciones", para ocupar empleos superiores, de los profesionales, y la necesidad de cubrir rápidamente los mandos inferiores de los Ejércitos, es decir, de improvisar las categorías de los que han de mandar en los frentes de combate, los pelotones, las secciones y las compañías, dentro de la organización castrense indispensable.

Aparecen así los Alféreces Provisionales, del lado nacional, a la vez que los denominados Tenientes en Campaña de la zona opuesta.

De esta manera se produce la incorporación civil de estudiantes, de bachilleres, de universitarios o de jóvenes con una formación intelectual, que si bien habían obtenido su empleo exclusivamente para el tiempo de duración de la campaña, permanecen y se transforman en profesionales en el bando vencedor por la necesidad de mantenerlos en filas debido a la situación internacional.

Así sucede que al comienzo de la transición, en el supuesto de que consideremos su comienzo con la muerte de Franco, se encontraban en lo más alto de los escalafones los militares anteriores a la gue- 
rra o incluso los cadetes que al comenzar ésta cursaban sus estudios en las respectivas Academias.

Pero los provisionales transformados estaban alcanzando también posiciones elevadas en la organización militar. Es decir, aquéllos que habian recorrido el territorio español conquistando posiciones, pueblos y ciudades, y dejando sobre los campos a tantos compañeros, mientras sufrían también por el destino de sus contrincantes, en tanto eran compatriotas suyos.

(Se partía de unas situaciones inolvidables. Como tengo una infinidad de nietos e incluso biznietos, creo que puedo permitirme, dentro de este propósito de recoger episodios personales simbólicos, relatar, como las batallitas del abuelo, mi primera impresión como Alférez Provisional de Infantería. De nuevo os pido perdón, pero os aseguro que es completamente distinto escuchar, con aburrimiento, antiguos relatos, que haber sido protagonista de los hechos remotos.

Siempre he sostenido que nuestra conducta en la vida, viene determinada, o debería venir, por el puesto que ocupamos, la categoría que hemos alcanzado o el respeto que llegamos a merecer. Ahí radica nuestra responsabilidad.

$Y$ cuando uno se ve con una estrella sobre el pecho $y$ se siente responsable de un número de hombres que nos obedecen porque confían en nosotros, se abandona el miedo o, mejor dicho, nos invade el nuevo temor de aparecer ante ellos como un cobarde. Hay que dar ejemplo, hay que ganarse la admiración, el respeto y el aprecio de nuestros subordinados. $Y$ esto debe suceder en toda la organización del Estado, militar y civil.

Durante la guerra, recuerdo mi incorporación como Alférez Provisional a la Unidad a que fui destinado y que estaba operando en el Frente de Teruel. Después de las mil aventuras que suponía el localizar y alcanzar nuestro destino, llegué al oscurecer y saludé a los Oficiales, todos Provisionales como yo, que tomaban su lata de sardinas alrededor de una hoguera. Me encomendaron el mando de la primera sección de la primera compañia, que mandaba otro Alférez Provisional de una Promoción anterior a la mía. Sólo recuerdo que se apellidaba Rubio. Hablamos de la operación del día siguiente, resguardados entre las paredes derrumbadas parcialmente de una paridera. Al amanecer, debíamos ocupar unas lomas cerca del río Alfambra. Rubio tenía aproximadamente veinte años. También estudiaba Derecho, era animoso, y en poco tiempo me relató su corta historia pasada y sus largas ilusiones para el futuro, cuando la guerra terminara. 
Por la mañana, apenas despuntó el día, recibimos la orden de avanzar. Yo marchaba al lado del Alférez Rubio y cruzamos rápidamente un terreno descubierto para ampararnos del intenso fuego en un pequeño muro de piedra. Llegamos jadeantes y nos tumbamos en el suelo, uno al lado del otro, procurando incrustarnos en el terreno. De pronto, percibí que me decía algo, tal vez una orden o una indicación sobre cuál había de ser nuestro próximo salto. Hablaba muy bajo, casi musitando, y me acerqué a su cara para oírle mejor. Me sorprendió el tono amarillo azulado que tomaba su rostro. $Y$ pude comprobar que no me hablaba a mí, sino que estaba rezando el "Señor mío Jesucristo".

Me tendió la mano que le sujeté, pero que pronto perdió su fuerza y su calor. Se extinguió así su vida y los demás seguimos avanzando. No puedo evitar que después de tantos años, yo me acuerde del Alférez Rubio, mi compañero de sólo unas horas. ¡Cuántos como él, de uno y otro lado, en aquel entrecruce de balas que ensombrecieron a España, no pudieron ver terminadas sus carreras, ni alcanzadas sus esperanzas, aunque eran unos chiquillos y sabían muy poco de cuanto había originado aquella tremenda tragedia entre hermanos.

No, no me digaís que estoy anticuado y que vivo de los recuerdos o que he permanecido aferrado a ellos. Al contrario, si aporto este testimonio personal que pudiéramos extender a muchos casos semejantes, es como símbolo del mérito que supone superarlo sin olvidarlo, evolucionar sin que el pasado se borre y llegar al convencimiento de que hay que adaptarse a los nuevos tiempos para colaborar todos al progreso de España, sin que puedan reproducirse hechos tan penosos.)

Los viejos políticos que fracasaron en su intento de mantener la paz o incluso propiciaron la guerra, deben ser ejemplo para los actuales, y los militares de hoy también necesitan extraer del pasado la lección ineludible.

Llegó la victoria y dentro de las Fuerzas Armadas se vivieron años de penurias $y$ dificultades, sin disfrutar de condiciones materiales privilegiadas, pero sí de una dignidad y una consideración que encerraban un gran valor para los miembros de aquéllas.

$Y$, pasados muchos años, como no podía por menos de suceder $y$ todos estábamos conscientes de ello, después de mil incidencias $y$ de graves acontecimientos como los atentados que alcanzaron incluso al Presidente del Gobierno, Almirante Carrero Blanco, llegaba o se continuaba la transición, producida por la muerte de Franco. Los adversarios contra los que se habia luchado y a quienes se venció en la guerra, vinieron a ganar la paz. Banderas, canciones y saludos denostados 
antes por una propaganda intensa y por el recuerdo de los viejos tiempos, aparecían ahora triunfantes $y$ retadores.

No era fácil para los componentes de las Fuerzas Armadas acomodarse a este cambio. Pero, como un nuevo sacrificio, consciente y necesario, se dispusieron a respetar la nueva situación y a colaborar con ella.

Es preciso recordar la influencia que sin duda produjo el mensaje postrero de quien les habia mandado durante la campaña: "Por el amor que siento por nuestra Patria, os pido que perseveréis en la unidad y en la paz y que rodeeis al futuro Rey de España, Don Juan Carlos de Borbón, del mismo afecto y lealtad que a mí me habéis prestado y le prestéis, en todo momento, el mismo apoyo de colaboración que de vosotros he tenido".

Como reflejo de estas palabras, otro mensaje, el primero de S.M. divulgado el 22 de noviembre de 1975, contiene recuerdos y esperanzas que las Fuerzas Armadas recogieron con enorme ilusión: "Es de pueblos grandes y nobles -decía- saber recordar a quienes dedicaron su vida al servicio de un ideal. España nunca podrá olvidar a quien como Soldado y Estadista ha consagrado toda la existencia a su servicio". Y más adelante proclamaba: "Como primer soldado de la Nación me dedicaré con ahinco a que las Fuerzas Armadas de España, ejemplo de patriotismo y disciplina, tengan la eficacia y la potencia que requiere nuestro pueblo".

Se había instaurado la Monarquía y las Fuerzas Armadas la acep$\tan$ y la apoyan de buen grado.

Sin detallar sentimientos y conductas o intentar la formulación de consideraciones psicológicas, llego a un momento en que voy a permitirme otra vez aportar una experiencia personal, de la que pueden deducirse mas amplias consecuencias, pues a mi juicio constituye un punto clave en este estudio del papel que las Fuerzas Armadas desempeñaron en la transición.

En 1976 había pasado yo a ocupar la Subsecretaría del Ministerio de Información y Turismo. Y recuerdo que, paseando por delante del Palacio de Congresos y Exposiciones, Alfonso Osorio, Andrés Reguera y yo, analizamos y comentamos los propósitos de que el Presidente Adolfo Suárez se reuniera con los Ministros militares y Altos cargos de la Milicia para explicarles sus propósitos, descubrirles sus planes de transformación política y recabar su comprensión y ayuda en momentos delicados de la vida nacional, cuando era necesario evolucionar hacia un nuevo sistema democrático, con la colaboración de todos los españoles. 
Adolfo Suárez y Alfonso Osorio habían cambiado ya impresiones sobre estos propósitos, $y$ tanto Andrés Reguera como, yo coincidimos en la posibilidad de llevarlo a cabo. Desde luego, no era un paso necesario e incluso podía presentar riesgos y complicaciones; pero nos encontrábamos en momentos delicados en que no parecía aconsejable rechazar transaciones, acuerdos y consensos.

Esta idea no suponía dar innecesarias muestras de subordinación a las Fuerzas Armadas, ni reconocerlas como un poder fáctico -aunque lo fueran- sino un gesto de buena voluntad que podría dar los mejores resultados.

Los propósitos siguieron adelante y el 8 de septiembre de 1976, la reunión se celebró en la Presidencia del Gobierno, entonces en Castellana, 3.

Mis servicios en el Ministerio del Ejército en diferentes destinos y durante 20 años al lado de seis Ministros, me permitían conocer y tratar a varios militares importantes de los que iban a acudir a la convocatoria.

El ambiente entre ellos era de espectación y de recelo a la vez. Como dicen en un libro Julio Merino ualli están los Generales de Franco, con sus caras, sus ilusiones perdidas y sus medallas ganadas frente al marxismo". Veinticinco Generales y Almirantes que veían tal vez al Presidente Suárez como un joven arriesgado y decidido, dispuesto a llevar a cabo una liquidación del pasado y una transformación profunda de la situación, que por fuerza había de originar cierta inquietud a los aún vencedores de la guerra.

- "Este muchacho nos va a oir», me dijo uno de los citados, con quien había tenido una próxima relación como subordinado. En general el clima era tenso y el que más y el que menos observaba una actitud recalcitrante, con el desconcierto del cambio y el reconocimiento de que había de realizarse. Aferrados a un pasado difícil de olvidar y convencidos de la necesidad de preparar un futuro distinto.

Pero la reunión fue un éxito. Por el mismo conducto anterior pude enterarme de la brillantez, naturalidad y acierto con que Adolfo Suárez les había explicado clara y sinceramente la situación, la necesidad de abordar una abierta transición hacia la democracia y la obligación que a todos afectaba de colaborar en esta difícil empresa de la reforma política.

De tal manera entusiasmó a los reunidos que algunos de ellos profirieron expresivos y sonoros juicios de elogio sobre el Presidente del Gobierno y sus ideas, merecedoras de ser ayudadas sin reservas. 
Pero, a partir de ese momento, los acontecimientos se desarrollaron de una forma que resultó decisiva para el futuro de la participación de las Fuerzas Armadas en el proceso de la transición política.

Es cierto que, a veces, por una parte se dice más de lo que se quiere decir, y por otra parte se entiende más de lo que se dice, porque más es lo que se desea oír. El caso es que los Ministros militares y las superiores Autoridades de la Milicia, después de la decisiva y afortunada reunión, cursaron informaciones y circulares a los Generales, Jefes, Oficiales y Suboficiales a sus órdenes con los resultados que se derivaban de aquella especie de acuerdo no escrito, para general conocimiento de los Ejércitos.

Por supuesto, la reforma se haría partiendo de la legalidad vigente y a través de los procedimientos previstos en las Leyes Fundamentales.

En cuanto al tema de los partidos políticos, el Presidente Suárez parece que fue rotundo, o al menos así lo entendieron los presentes: «Estaros tranquilos, que en ese punto yo pienso como seguramente pensáis vosotros: Partidos políticos, sí; pero no Partido Comunista". Y, al parecer, asi se lo dijo también a Alfonso Osorio, pues desde el primer momento se habia dado por supuesto que las modificaciones introducidas en el Código Penal no autorizaban la legalización del Partido Comunista.

Han surgido dudas en cuanto a la rotundidad de esta afirmación. El desaparecido Capitán General Gutiérrez Mellado sostuvo que no se expresó tan taxativamente y que, en todo caso, la posterior acomodación de los Estatutos del Partido Comunista, permitió que quedaran comprendidos en la legislación vigente.

Es posible que esta situación se comentara con algún Ministro militar o se hicieran advertencias parciales.

Pero lo cierto es que nada se hizo abiertamente ni se celebró una nueva reunión para aclarar este extremo y hacer saber la decisión que iba a tomarse, a los mismos que, por lo menos, habían creído entender una promesa formal de lo contrario.

En las Fuerzas Armadas se había producido una sensación de alivio en medio de las naturales preocupaciones y dificultades de adaptación, de superación de nostalgias y de transformaciones de mentalidad.

Sin embargo, se llegó después a experimentar un profundo disgusto al entender que no se había contado con ellas para tan radical cambio de actitud. La primera reunión con los militares no había sido necesaria, pero al haberse celebrado, la segunda parecia ineludible. 
De esas consecuencias lamentables de lo que se consideraba una falta de atención y hasta de engaño patente, también me correspondió ser testigo de lo que voy a relatar, siguiendo el sistema de poner de manifiesto hechos generales a través de impresiones subjetivas.

Era yo entonces Subsecretario del Ministerio de Información y Turismo, cuya cartera ostentaba Andrés Reguera Guajardo. El día 8 de abril de 1977, recibí una llamada del Ministro indicándome que aquella tarde debía trasladarme al Ministerio de la Gobernación para asistir a una reunión en sustitución suya -pues se encontraba fuera de Madridy que después le informara de lo tratado. Pensé, pues, que íbamos a acudir representantes de varios Departamentos, pero sin sospechar siquiera con qué objeto.

Llegué al Ministerio, en la Calle de Amador de los Ríos, y me recibió enseguida en un despacho el Ministro Rodolfo Martín Villa. Estábamos sólos, sin el resto de asistentes que yo había imaginado.

El Ministro me dijo:

- "Te he llamado para que en vuestro Ministerio se instrumente con rapidez la forma de dar la noticia del reconocimiento del Partido Comunista».

Mi sorpresa fue grande. Por eso me atreví a preguntar: las promesas?".

- ¿Y los militares? ¿Se les ha dicho que cambiaron los planes y

Estoy seguro de que lo hubieran comprendido perfectamente. No sólo por la habilidad de Suárez y su indudable poder para ser convincente, sino porque la explicación era sencilla y lógica. Frente a la impresión de rechazo que instintivamente dominaba a los militares con respecto al comunismo al que habían combatido y creído vencer en los frentes de combate como una obsesión, se tenía que imponer la realidad de que la democracia no podía hacer excepciones y exigía el reconocimiento de todos los partidos políticos de cualquier signo, que tuvieran sus Estatutos adaptados a la legalidad vigente y se comprometieran a aceptar el juego democrático. Además, era preferible conocer el número de sus afiliados, su fuerza y sus propósitos, que dejarlos en la ignorancia, actuando de forma clandestina y llevando a cabo en la sombra una lucha sorda.

Los militares se hubieran convencido de esa necesidad, razonablemente explicada y quedarían de nuevo agradecidos de que se les comunicara y advirtiera de ese cambio de actitud, justificado y conveniente. Habría continuado el entusiasmo que para entregarse plena- 
mente en la empresa de la transición, les inspiró la primera reunión mantenida con el Presidente del Gobierno y ampliamente divulgada.

¿Qué había sucedido?

Al parecer, y según se deducia de una nota preparada en el Ministerio de la Gobernación como base para la difusión de la noticia del reconocimiento, la Fiscalia había informado favorablemente los Estatutos del Partido Comunista Español y no existían obstáculos legales para que pudiera ser incluido entre los oficialmente reconocidos.

Pero hube de insistir:

- «Si no se le ha dicho a la cúpula militar, ¿será procedente que se enteren por los medios de comunicación? ¿No es grave que llegue a su conocimiento como un hecho consumado, algo tan radicalmente distinto de las promesas que se habian hecho?».

Rodolfo Martín Villa se quedó pensativo. Me pidió que esperara un momento y dejó el despacho durante un rato.

Cuando volvió se limitó a decirme:

- "Ese tema ya está solucionado".

No es del caso intentar descubrir ahora cómo, por quién y cuándo se pensó que estaba solucionado.

Se ha escrito bastante sobre este extremo y entre las distintas versiones no deja de producirse una evidente contradicción. Pero lo cierto es que se trata de un episodio clave de la transición, visto desde la participación que en ella tuvieron las Fuerzas Armadas. Un episodio decisivo del que se derivaron importantes consecuencias.

Hay ocasiones en que alguien tiene que sacrificarse y dar consejos o tomar decisiones que en definitiva pueden resultar útiles, pero que arrastran la crítica y la censura. Es posible que en este caso existiera un sacrificado.

Alfonso Osorio manifiesta en un interesante libro la preocupación que le embargaba y cómo había insistido en que legalizar el Partido Comunista sin contar con la comprensión del Ejército, podía ser gravísimo.

Las incidencias de la determinación fueron numerosas y grande el malestar de quienes se consideraban engañados. Estoy seguro de que no fue esto lo que se pretendió, pero el resultado fue deplorable $y$ de una trascendencia extraordinaria.

La legislación que afectaba a las Fuerzas Armadas, había iniciado medidas específicas y limitativas. Y el Real Decreto-Ley de 8 de fe- 
brero de 1977 estableció fundamentales prohibiciones para que ocuparan cargos políticos los que con carácter profesional forman parte de las Fuerzas Armadas. Una medida de la que, por cierto, se exceptuaba al militar y político que la inspiro.

Sucedieron muchas cosas más. La inquietud militar se había manifestado en distintas ocasiones y permanecía latente la desilusión por lo que se consideraba un agravio inexplicable. Atentados terroristas contra militares y miembros de las Fuerzas Armadas de Orden Público, secuestro del Teniente General Villaescusa y de Antonio María de Oriol y Urquijo, Presidente del Consejo de Estado; intento de expulsión de las filas del Ejército de los Tenientes Generales de Santiago e Iniesta, con apoyo en una Ley de Regulación de Escalas del año 1943, totalmente inaplicable al caso, por lo que la decisión hubo de ratificarse; dimisión del Ministro de Marina y dificultades para sustituirle; operación "Galaxia" y campañas de cierta prensa que excitaba los ánimos y originaban confusión; nombramientos en la Cúpula Militar que producían un malestar evidente por su anormalidad; reingreso de los militares pertenecientes a la UMD...

$Y$ un hecho importante, de indudables repercusiones, el viaje oficial de SS.MM. los Reyes al País Vasco, con los graves incidentes en la Casa de Juntas de Guernica.

Coincidiendo con esta visita a Euskadi se produce el asesinato del Ingeniero Jefe de la Central Nuclear de Lemóniz, José Maria Ryan.

El 27 de enero de 1981, el Presidente del Gobierno Adolfo Suárez dimite ante S.M. el Rey y en el mensaje que posteriormente dirija a los españoles hay un párrafo en el que dice:

"Me voy, pues, sin que nadie me lo haya pedido. Creo, por tanto, que ha merecido la pena, pero, como frecuentemente ocurre en la Historia, la continuidad de una obra exige un cambio de personas y yo no quiero que el sistema democrático de convivencia sea, una vez más, un paréntesis en la Historia de España... Tenemos que mantener la esperanza, convencidos de que las circunstancias seguirán siendo difíciles durante algún tiempo".

Palabras significativas en las que se han querido descubrir una significación aún mayor.

$Y$, de pronto, el 23 de febrero de 1981, se produce el asalto al Congreso de los Diputados por el Teniente Coronel Tejero, al frente de un grupo de Guardias Civiles.

Pero me parece que debo ir terminando para no abusar demasiado de vuestro tiempo, de vuestra atención y de vuestra paciencia. 
Alguien pensará, quizá, que en este afán de ser ya muy breve, puedan influir mis deseos de no detenerme en los acontecimientos de aquel día y aquella noche tan importantes para las Fuerzas Armadas y para España. Y el que así lo piense, es posible que tenga razón.

Funesto fue el "pronunciamiento", pero no lo fue menos el desarrollo del Consejo de Guerra posterior.

Es posible que las Fuerzas Armadas se sintieran desmoralizadas. Pero no hay que desanimarse. Se han ido incorporando a ellas nuevas generaciones con todo el entusiasmo de su vocación y de su elevado espíritu.

Han desaparecido o estamos a punto de desaparecer ya, desde la más absoluta de las situaciones de reserva, los que creíamos que habíamos ganado una guerra. Vamos a unirnos, con muchos años de retraso a tantos muchachos de uno y otro bando que perdieron prematuramente la vida, en uno u otro bando, y nos dejaron a los demás la impresión de su muerte. Hemos tenido tiempo suficiente para comprobar que lo importante es ganar la paz y entregarse a su defensa con todas nuestras fuerzas.

Todo continúa y continuará también la perpetua reorganización de las Fuerzas Armadas que de una manera general tuvieron que participar con serenidad, patriotismo y comprensión en el proceso de la transición política española.

En ninguna forma puede admitirse la afirmación, a veces repetida en determinados sectores, según la cual la transición democrática en España se realizó a pesar de las Fuerzas Armadas. Todo lo contrario, éstas fueron precisamente el sostén para que se realizara el cambio que sin ellas tal vez ni hubiera sido posible. Aceptaron el proceso con todas las consecuencias, asumiendo lo que en ocasiones consideraban serios agravios y con el mérito indudable de que ello suponía renunciar a un pasado en el que había tenido una activa participación.

En consecuencia, carecen de fundamento la acusación de antidemocráticos que a los Ejércitos suelen hacerse. Los nuestros, como todos los del mundo, constituyen orgánicamente una estructura jerarquizada y disciplinada que no permite el empleo de fórmulas democráticas de cara a su propia funcionalidad.

Ni la disciplina o la obediencia pueden someterse a votación, ni es la mayoría la que decide si una orden se cumple, una misión es correcta o una operación rechazable. Pero esto no supone, en absoluto, que la institución militar rechace los sistemas políticos democráticos con respecto a la Nación, en general, a la que sirven y cuya defensa tienen constitucionalmente encomendada. 
Me gustaría que pudiera deducirse esta conclusión a través de las impresiones personales que he tratado de transmitiros.

Se ha dicho que, "al fin y al cabo, existe la historia que uno ha vivido, la que ha creído vivir y la que cuenta que vivió".

Sólo aspiro a que en mi intervención de esta mañana se produzca la coincidencia de las tres.

Muchas gracias. 